\title{
Forgery in Research
}

\author{
Sadaf Shahab ${ }^{1, *}$, Tahir Sultan Shamsi ${ }^{2}$ \\ ${ }^{1}$ Department of Molecular Biology, National Institute of Blood Disease \& Bone Marrow Transplantation, Karachi, Pakistan. \\ ${ }^{2}$ Department of Clinical Hematology, National Institute of Blood Disease \& Bone Marrow Transplantation, Karachi, Pakistan.
}

According to one definition "intention or gross negligence leading to fabrication of the scientific message or a false credit or emphasis given to scientist" is known as forgery or misconduct in science [1]. There are three types of misconduct in science, fabrication, falsification and plagiarism. Fabrication is making up and recording of results. Minor form of fabrication is citation in references where references is either not included or not reinforcing the argument or sometime totally against the argument. Falsification is changing or misinterpreting material, equipment or protocol. Plagiarism is utilization of some ones ideas, process, result or words without giving him proper credit [2].

There are two main reasons of doing forgery one is career pressure another is ease of fabrication. When everything financial gain, fame and grants all are depending on publication then scientist become more prone to misconduct and forgery [3]. On the other hand, when just sometime paper and pencil gives your required result in a moment then why waste time efforts and money for real results. After all both of them gives publication.

In routine practice of research, there are many misrepresentations where dubious findings are very common. The building of research rests on trust. A belief that, everything written on journal paper is completely true and flawless. People report their experiments and audience around the globe take it as most authenticated material and repeat them without hesitation. Although replication and reproducibility is backbone in research but artifacts, noise and other problems some time make it very difficult to reproduce the same experiment. Not only experimentation but biasness, loss of randomization, selection of wrong study design all are the pitfall and accelerate the process of fogery by one way or another. On other hands there are many gray areas in research where scientists are not doing any fraud by will but little misinterpretation as results are not very clear and they make it clear by changing in scientific data because of being human or some time eager to do more [4]. Scientist some time enhance or amplify the color or background to make their result more evident but it ended up in more accusation and may result in "societal injury" [5]. Therefore, now it is suggested not to do so as it

\footnotetext{
*Address correspondence to this author at the Department of Molecular Biology, National Institute of Blood Disease \& Bone Marrow Transplantation, Karachi, Pakistan. E-mail: sadaf_shahab99@yahoo.com
}

ended up on more accusation on them as they are trying to show those result which are not present or easy to detect. The whole process of research is lengthy, complicated and full of measurements and numerical data. There is no red light which suddenly blink or no alarm which start ringing on fraudulent data.

There are lot of stories associated with forgery of data which causes lot of resource wastage ,financial burden, wrong conclusion and finally wrong policies and protocol for patient. In 1998, wakefield published his research in lancet about connection between MMR vaccine and autism. This badly shaken the trust of parents on vaccine and many of them start discontinuation of vaccine which causes rise in disease. Later on it was found that wakefield was working for a lawyer who want to sue the vaccine vendors [6].

In one case of Alfred tens of millions and two decades lost in an attempt to find out relation between infant sleep apnea and sudden infant death syndrome SIDS. It takes 22 years to uncover the story when waneeta hoyt, mother of children and series killer was arrested [7].

Pitdown hoax was the most historical fraudulent case where a falsified fossil of skull was presented as a connecting link between apes and human and it takes more than forty years to discover the fraud [8].

Satos Japanese scientific fraud was the biggest of its own type. He wrote 200 papers about bone fractures before his suicide in 2016 .Team of four researchers worked day and night up to four years to expose his fraud Sato did more than 33 clinical trials and performed meta-analysis and produced 5894 patents [9].

Another frawd which recently come under the light is of Beltrami et al. 2001 who claimed that adult heart cells are able of mitosis after myocardial infraction [10].

With the advancement of internet, more and more resources are available to find out plagiarism and duplication of research material.one such tool is introduced in 2006 by university of texas southwestern. All of the entries find out by text mining algorithm eTBLAST [11]. Another tool which clearly helps in find out fraudulent data is error analysis. Measurements when ever taken in duplicates often creates 
little variation these variations must follow some mathematical and statistical properties [12]. Variation from such properties may help to detect problem in data. Another important tool is turn it in which produce a complete report of word to word plagiarism report in few minutes

Many steps have been taken by authorities to make research more transparent. As it is the primary responsibility of journals to ensure data safety. Most of the journals strictly follow COPE Committee on Publication Ethics. Journals strictly followed peer review system. A letter from Ethical committee is now a part of manuscript and no paper could be published without the prior approval from ethical review committee. Author wise work distribution that is what is done by who is also asked before submission in order to discourage ghost authorship. Conflict of interest is also very important which clearly ask any sort of financial gain or promotion. Above all a sword of ethics should be there to make the route of research more open and clean.

The recommendations to stop forgery in research are to relaxing pressure of publication from scientist and breaking vicious cycle of more rapid publication. Reviewer is also very important in doing so. Now a days, many journals claim for rapid publication and give very less time of 10 -15 days for reviewer. This is not possible for reviewer to complete this process in such a short notice. Reviewers are very busy and not easy for them to complete review process in short time. Reviewers are the first line defense in combating forgery. They are the one who first saw manuscript and must have adequate time to review it thoroughly. They must have time to analyze it critically and must have plenty of time to investigate about novelty, originality and authenticity of data.

\section{CONFLICT OF INTEREST}

Declared none.

\section{ACKNOWLEDGEMENTS}

Declared none.

\section{REFERENCES}

[1] Nylenna M, Andersen D, Dahlquist G, Sarvas M, Aakvaag A. Handling of scientific dishonesty in the Nordic countries. National Committees on Scientific Dishonesty in the Nordic Countries. Lancet 1999; 354 (9172): 57-61.
[2] Smith R. What is research misconduct? In: White C, Ed. The COPE Report 2000- Annual Report of the Committee on Publication Ethics. UK: BMJ Books 2000.

[3] Goodstein D. Scientific misconduct. Academe 2002; 8(1): 28-31.

[4] Faneli D. How Many scientists fabricate and falsify research? A systematic review and meta-analysis of survey data. PloS One 2009; 4(5): e5738.

[5] Bik EM, Casadevall A, Fang FC. The prevalence of inappropriate image duplication in biomedical research publications. mBio 2016; 7(3): e00809-16.

[6] Sathyanarayana Rao TS, Andrade C. The MMR vaccine and autism: Sensation, refutation, retraction, and fraud. Indian J Psychiatry 2011; 53(2): 95-6.

[7] Steinschneider A. Prolonged apnea and the sudden infant death syndrome: Clinical and laboratory observations. Pediatrics 1994; 93(6): 944.

[8] Spencer F, Ed. The Piltdown Papers, 1908-1955: The Correspondence and Other Documents Relating to the Piltdown Forgery. USA: Oxford University Press 1990.

[9] Kantha SS. Suicides of 84 Newsworthy Japanese between 1912 and 2015. Int Med J 2015; 22(5): 352-7.

[10] Drazen JM. Expression of Concern: Beltrami AP, Urbanek K, Kajstura J, et al. Evidence that human cardiac myocytes divide after myocardial infarction. N Engl J Med 2001; 344: 1750-7 and Quaini F, Urbanek K, Beltrami AP, et al. Chimerism of the transplanted heart. N Engl J Med 2002; 346: 5-15.

[11] Lewis J, Ossowski S, Hicks J, Errami M, Garner HR. Text similarity: An alternative way to search medline. Bioinformatics 2006; 22(18): 2298-304.

[12] Haefner JW, Ed. Modeling Biological Systems: Principles and Applications. USA: Springer 1996; pp. 186-9.

Received: December 31, 2018

Accepted: January 28, 2019 